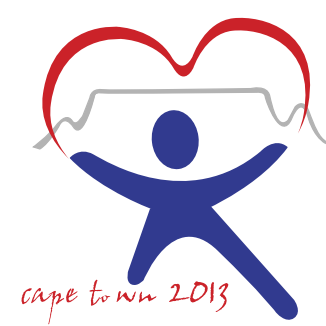

$6^{\text {th }}$ WORLD CONGRESS

Paediatric Cardiology \& Cardiac Surgery

17 - 22 February 2013, Cape Town, South Africa

\title{
The World Congress of Paediatric Cardiology and Cardiac Surgery: "The Olympics of our Profession"
}

\author{
Christopher Hugo-Hamman, ${ }^{1}$ Jeffery Phillip Jacobs ${ }^{2}$ \\ ${ }^{1}$ Chairman, $6^{\text {th }}$ World Congress of Paediatric Cardiology and Cardiac Surgery (2013); Christiaan Barnard Memorial \\ Hospital, Cape Town, South Africa; ${ }^{2}$ Editor, HeartWeek Issue of Cardiology in the Young; Johns Hopkins Children's \\ Heart Surgery, All Children's Hospital and Florida Hospital for Children, Florida, United States of America
}

\begin{abstract}
The first World Congress of Paediatric Cardiology was held in London, United Kingdom, in 1980, organised by Dr Jane Somerville and Prof. Fergus Macartney. The idea was that of Jane Somerville, who worked with enormous energy and enthusiasm to bring together paediatric cardiologists and surgeons from around the world. The 2nd World Congress of Paediatric Cardiology took place in New York in 1985, organised by Bill Rashkind, Mary Ellen Engle, and Eugene Doyle. The 3rd World Congress of Paediatric Cardiology was held in Bangkok, Thailand, in 1989, organised by Chompol Vongraprateep. Although cardiac surgeons were heavily involved in these early meetings, a separate World Congress of Paediatric Cardiac Surgery was held in Bergamo, Italy, in 1988, organised by Lucio Parenzan. Thereafter, it was recognised that surgeons and cardiologists working on the same problems and driven by a desire to help children should really rather meet together. A momentous decision was taken to initiate a Joint World Congress of Paediatric Cardiology and Cardiac Surgery. A steering committee was established with membership comprising the main organisers of the four separate previous Congresses, and additional members were recruited in an effort to achieve numerical equality of cardiologists and surgeons and a broad geographical representation. The historic 1st "World Congress of Paediatric Cardiology and Cardiac Surgery" took place in Paris in June, 1993, organised by Jean Kachaner. The next was to be held in Japan, but the catastrophic Kobe earthquake in 1995 forced relocation to Hawaii in 1997. Then followed Toronto, Canada (2001, organised by Bill Williams and Lee Benson), Buenos Aires, Argentina (2005, organised by Horatio Capelli and Guillermo Kreutzer), and most recently Cairns, Australia (2009, organised by Jim Wilkinson). Having visited Europe (1993), Asia-Pacific (1997), North America (2001), South America (2005), and Australia (2009), and reflecting the "African Renaissance", the World Congress is coming to Africa. The 6th World Congress of Paediatric Cardiology and Cardiac Surgery will be held in Cape Town, South Africa, from 17 to 22 February, 2013. Cape Town is a sublime and compelling African destination with irresistible appeal. The South African Heart Association is the host. Information about The 6th World Congress of Paediatric Cardiology and Cardiac Surgery can be found at http://www.pccs2013.co.za.
\end{abstract}

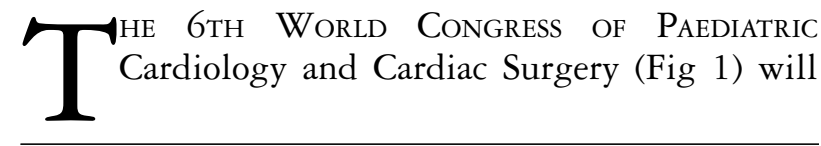

Correspondence to: Dr C. Hugo-Hamman, Christiaan Barnard Memorial Hospital, 87 Loop Street, Cape Town 7806, South Africa. Tel:+27 21422 4851; Fax: +27 21422 4799; E-mail: christopher.hugo@medinet.co.za be held in Cape Town, South Africa, from 17 to 22 February, 2013. Cape Town is a sublime and compelling African destination with irresistible appeal. The South African Heart Association is the host, and we look forward to welcoming delegates to our city, our country, and the African continent. 
Information about The 6th World Congress of Paediatric Cardiology and Cardiac Surgery can be found at http://www.pccs2013.co.za.

The 6th World Congress will build on the interdisciplinary educational and scientific foundations established through the five previous World Congresses. The history of this event reflects a unity of purpose between surgeons and physicians. The first World Congress of Paediatric Cardiology was held in London, United Kingdom, in 1980, organised by Dr Jane Somerville and Prof. Fergus Macartney. The idea was

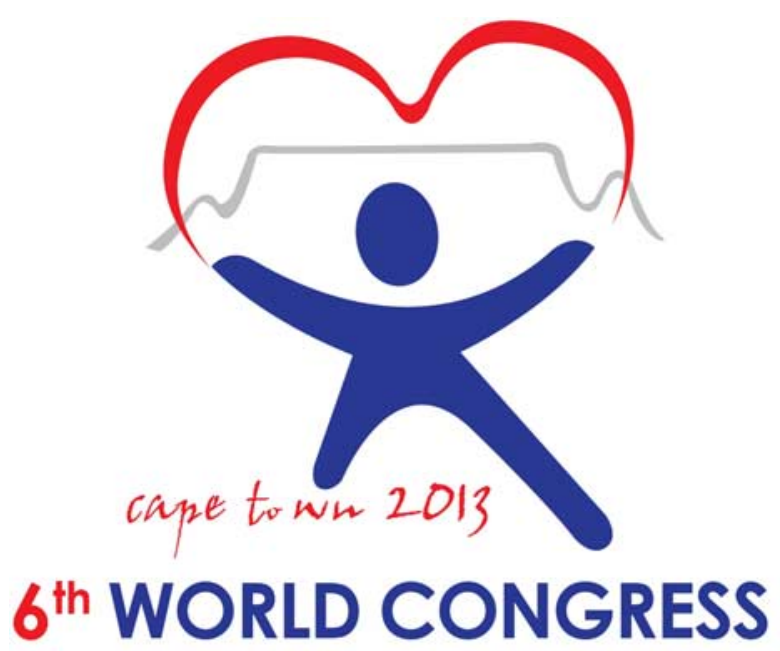

Paediatric Cardiology \& Cardiac Surgery

Figure 1. that of Jane Somerville, who worked with enormous energy and enthusiasm to bring together paediatric cardiologists and surgeons from around the world.

The 2nd World Congress of Paediatric Cardiology took place in New York in 1985, organised by Bill Rashkind, Mary Ellen Engle, and Eugene Doyle. The 3rd World Congress of Paediatric Cardiology was held in Bangkok, Thailand, in 1989, organised by Chompol Vongraprateep. Although cardiac surgeons were heavily involved in these early meetings, a separate World Congress of Paediatric Cardiac Surgery was held in Bergamo, Italy, in 1988, organised by Lucio Parenzan. Thereafter, it was recognised that surgeons and cardiologists working on the same problems and driven by a desire to help children should really rather meet together. A momentous decision was taken to initiate a Joint World Congress of Paediatric Cardiology and Cardiac Surgery. A steering committee was established with membership comprising the main organisers of the four separate previous Congresses, and additional members were recruited in an effort to achieve numerical equality of cardiologists and surgeons and a broad geographical representation. Table 1 shows the current membership of the Steering Committee of The World Congress of Paediatric Cardiology and Cardiac Surgery.

The historic 1st "World Congress of Paediatric Cardiology and Cardiac Surgery" took place in Paris in June, 1993, organised by Jean Kachaner. The next was to be held in Japan, but the catastrophic Kobe earthquake in 1995 forced relocation to Hawaii in 1997. Then followed Toronto, Canada (2001, organised

Table 1. Steering Committee of The World Congress of Paediatric Cardiology and Cardiac Surgery (2012).

\begin{tabular}{lllll}
\hline First name & Last name & Specialty & Country & Continent \\
\hline Zohair & Al Halees & Surgery & Saudi Arabia & Asia \\
Lee & Benson & Cardiology & Canada & North America \\
Horacio & Capelli & Cardiology & Argentina & South America \\
Sertac & Cicek & Surgery & Turkey & Europe/Asia \\
John & Deanfield & Cardiology & United Kingdom & Europe \\
Junbao & Du & Cardiology & People's Republic of China & Asia \\
Welton & Gersony & Cardiology & United States of America & North America \\
Christopher & Hugo-Hamman & Cardiology & South Africa & Africa \\
Krishna & Iyer & Surgery & India & Asia \\
Jeffrey & Jacobs & Surgery & United States of America & North America \\
Marcelo & Jatene & Surgery & Brazil & South America \\
Tom & Karl & Surgery & Australia & Australia/Oceania \\
Hiromi & Kurosawa & Surgery & Japan & Asia \\
Heung Jae & Lee & Cardiology & Korea & Asia \\
Maurice & Leung & Cardiology & Hong Kong & Asia \\
Folkert & Meijboom & Cardiology & The Netherlands & Europe \\
Shakeel & Qureshi & Cardiology & United Kingdom & Europe \\
Jane & Somerville & Cardiology & United Kingdom & Europe \\
Susan & Vosloo & Surgery & South Africa & Africa \\
Pascal & Vouhé & Surgery & France & Europe \\
Gil & Wernovsky & Wilkinson & Cardiology & United States of America \\
James & Williams & Cardiology & Australia & North America \\
Bill & & Surgery & Canada & Australia/Oceania \\
\hline & & & North America \\
\hline
\end{tabular}


by Bill Williams and Lee Benson), Buenos Aires, Argentina (2005, organised by Horatio Capelli and Guillermo Kreutzer), and most recently Cairns, Australia (2009, organised by Jim Wilkinson). Having visited Europe (1993), Asia-Pacific (1997), North America (2001), South America (2005), and Australia (2009), and reflecting the "African Renaissance", the World Congress is coming to Africa.

Cape Town is now the beneficiary and provides an ideal meeting place for the global coalition of doctors, nurses, and health scientists who use research and technological development to provide better care for babies, children, and adults with congenital and acquired cardiac disease. The World Congress of Paediatric Cardiology and Cardiac Surgery is the major international scientific event for our global community and an opportunity to highlight and review 4 years of research and technological developments in basic sciences, translational and clinical research, and therapeutic interventions. The international faculty now includes over 300 members and promises an exceptional scientific programme across the different disciplines from interventions, imaging, procedures, and surgery through to critical care.

The World Congress of Paediatric Cardiology and Cardiac Surgery supports the notion that all children with cardiac disease ought not to be denied the benefits of medical science, and our vision is to use this Congress as a platform to spread cardiac care to those children in regions without access. It is an occasion to emphasise the glaring inadequacies in delivery of cardiac care in many countries, and to use this global forum to find creative humanitarian solutions to develop new services in resource-poor environments.

Of course, the limitations to developing cardiac care in the presence of financial, managerial, and human resource constraints are problems shared with colleagues from wealthier nations. Science alone will not meet these challenges, and our Congress offers health policy planners, health system managers, and health economists a unique forum to find health systems solutions necessary to initiate, develop, and improve cardiac care for children.

There are six "tracks" for delegates to follow over the 5 days of the Congress:

- Interventional cardiology (with live case transmission)

- Health systems and heart disease

- Cardiac surgery, anaesthesia, and intensive care

- Adult congenital heart disease

- Cardiology and the imaging revolution

- Nursing science.

Parallel sessions mean delegates can switch across tracks as they please. All the scientific sessions are open to any delegate; in other words, delegates are not hostage to any of the five tracks on any day or at any time. The programme is a mix of popular plenary sessions, debates, lectures, and live cases. The Congress is enriched by the participation of many institutions that have taken the opportunity to arrange their own breakfast or evening symposia. Over 1400 abstracts have been accepted either for oral presentation or as $\mathrm{E}$ posters in the digital "abstract café".

Numerous international societies and institutions have shared the vision that "The World Congress of Paediatric Cardiology and Cardiac Surgery", held every 4 years, is the defining international event in the lives of those of us committed to helping children with cardiac disease and adults with congenital cardiac disease. This issue of Cardiology in the Young is dedicated to HeartWeek in Florida, and the organisers of HeartWeek are pleased to cancel our 2013 meetings to support the World Congress in South Africa. In fact, several institutions and societies cancelled their own meetings in 2013 in favour of The World Congress, and in that regard we acknowledge the magnanimous gestures of the Children's Hospital of Philadelphia, All Children's Hospital of Saint Petersburg, Florida, Johns Hopkins Medicine, and the World Society for Pediatric and Congenital Heart Surgery. Each of these organisations will actively participate in the 6th World Congress of Paediatric Cardiology and Cardiac Surgery. A special session on Surgery for Rheumatic Heart Disease will be held with The World Society for Pediatric and Congenital Heart Surgery.

With Table Mountain as a backdrop, the "mother city" is instantly recognisable as a major international tourist destination. The competing attractions of Robben Island, the Table Mountain National Park, the Victoria and Alfred Waterfront, Kirstenbosch Botanical Gardens, the beaches, and the winelands offer visitors to Cape Town a formidable choice of historical, cultural, botanical, and fun destinations. The game reserves with their vast array of African wildlife are not far off and provide delegates with the perfect reason to extend their visit to South Africa.

The World Congresses have been successful in bringing together delegates from many countries across very different health-care environments for stimulating educational meetings where individuals can network and learn from one another. The World Congress has been effective in fostering a collegial spirit between the many specialities involved in children's heart health, providing a range of opportunities for trainees and established practitioners to upgrade skills, cooperate, and collaborate for the good of children with cardiac disease around the world. Bigger is not necessarily better, but the 6th World Congress promises to be a very worthwhile experience and important global event. You too can be an "Olympian" in Cape Town in February! 